\title{
Catheter-related infections in a northwestern São Paulo reference unit for burned patients care
}

\begin{abstract}
Despite improvements in care and rehabilitation of burned patients, infections still remain the main complication and death cause. Catheter-related infections are among the four most common infections and are associated with skin damage and insertion site colonization. There are few studies evaluating this kind of infection worldwide in this special group of patients. Padre Albino Hospital Burn Care Unit (PAHBCU) is the only reference center in the Northwestern São Paulo for treatment of burned patients. This paper presents the results of a retrospective study aiming at describing the epidemiological and clinical features of catheter-related infections at PAHBCU.
\end{abstract}

Keywords: catheter, infections, burns, bacteria.

[Braz J Infect Dis 2010;14(2):167-169]@Elsevier Editora Ltda.

\section{INTRODUCTION}

Despite many advances on severely burn victims' care, infections still remain the mortality leading cause. ${ }^{1}$ Immunological impairment due to mechanical injury predisposes these patients to wound colonization and infection by different microorganisms. ${ }^{2}$ In addition, individuals with major burns are especially in need of invasive devices, such as total parenteral nutrition tubes, vesical catheters and central venous catheters. ${ }^{3}$ Indeed, burned patients have been referred to in literature as being at greater risk of developing catheterrelated infections, once catheter insertion may be placed in burned areas with high bacterial density. ${ }^{4}$

There are not well defined criteria for catheter infections in burned patients, although these complications are one of the leading causes of infection. ${ }^{5}$ Bacteremia, severe sepsis, and septic shock are the main catheter infections consequences, followed by septic tromboflebitis, distal embolization, and endocarditis. Therefore, catheter related-infections are associated with important morbidity and mortality, increased hospital staying, and elevated health care costs. ${ }^{6}$

Nevertheless, preventive recommendations in catheter-related infections are still rare and conflicting in this group of patients, justifying the need for further epidemiological and clinical characterization of such occurrences. ${ }^{7}$ Herein we present the results of a retrospective study aiming at describing the epidemiological and clinical features of catheter-related infections in a reference burn care center unit in Southeast Brazil.

\section{MATERIAL AND METHODS}

After obtaining approval from the Ethics Research Committee (CEP-FAMECA 0037.0.218.000-09) we carried out a retrospective catheter-related infections study during a tree year period (January 2005 to December 2007) in Padre Albino Hospital Burn Care Unit. The definition criteria for catheter-related infections were obtained from the Centers for Disease Control and Prevention - Atlanta/ EUA (CDC). Infection episodes were analyzed trough medical archives.

All central-line catheters were placed at PAHBCU. Insertions and drape care are standard, and were not changed throughout the study period and meet CDC recommendations. ${ }^{8}$ Catheter tip cultures were done based on Maki technique. ${ }^{9}$ All patients showing at least one catheter-related infection episode in subclavian vein, internal jugular vein, femoral vein, or brachial vein were included. Patients coming from longer than 48 hours stay in other hospitals, with or without central-line catheterization, were excluded.
Authors

Cláudio Penido Campos Júnior $^{1}$

Patrícia Sanches ${ }^{2}$

Elizabete Aparecida Tedokon $^{2}$

Ana Carolina Remondi Souza $^{3}$

Ricardo Luiz Dantas Machado ${ }^{3}$

Andréa Regina Baptista Rossit $^{3}$

${ }^{1}$ Master's student - Health Sciences Post-graduation Program of the Faculdade de Medicina de São José do Rio Preto, FAMERP Coordinator of the Hospita Epidemiology Center of

Faculdade de Medicina de Catanduva, FAMECA

${ }^{2}$ Associated Nurses of the Hospital Epidemiology Center of Faculdade de Medicina de Catanduva ${ }^{3}$ Adjunct Professors at the Department of Dermatological, Infectious, and Parasitical Diseases - Faculdade de Medicina de São José do Rio Preto, FAMERP, São José do Rio Preto, SP, Brazil

Submitted on: 06/03/2009 Approved on: 09/09/2009

Correspondence to: Cláudio Penido Campos Júnior

Centro de Epidemiologia Hospitalar da Faculdade de Medicina de Catanduva Avenida São Vicente de Paulo, 1455 - Parque

Iracema

CEP: 15809-145

Catanduva - SP - Brazil

Phone/Fax: 017

355313200

E-mail: claudio.penido@ terra.com.br

We declare no conflict of interest. 
Patient's data were collected and recorded on forms. Demographics, clinical-epidemiological, catheter-related, and evolutive aspects were studied. Results were not statistically described.

\section{RESULTS}

Eight-hundred and eight six patients were admitted at PAHBCU in this study period, with a 12 day mean staying period. Of these, $40(4.51 \%)$ patients had at least one catheter-related infections documented. Twenty patients (50\%) were female, age ranged from 4 to 79 years (mean age $=37.1$ years; standard deviation $= \pm 19.7$ years $)$, with 30 (75.0\%) burn episodes occurring at home and 10 (25.0\%) episodes at work. More than $50 \%$ of accidents were caused by from flame, followed by energy contact, boiling water, and electric source.

Associated diseases were present in 23 patients (57.5\%), with diabetes mellitus being the most common condition $(12.5 \%)$. Catheter-site signs of infection with sepsis syndrome was the most common finding $(47.5 \%)$, followed by catheter-site signs of infection without sepsis syndrome $(42.5 \%)$, as determined according to statements from Survival Sepsis Campaign, ${ }^{10}$ Only four patients had signs of infection at the site of catheter insertion and severe sepsis $(10 \%)$.

Most patients $(72.5 \%)$ had only one central catheter, while $20 \%$ had two catheters, and only $7.5 \%$ were exposed to tree or more central-lines. Subclavian and internal jugular veins were the most prevalent site of catheter insertions (75\%), whereas femoral artery was used for the other ones. Only one $(2.5 \%)$ patient had a double-lumen catheter inserted and the remaining patients had single-lumen devices. Unburned areas were the insertion catheter sites in most patients (65\%) and almost seventy percent (69.8\%) of them were maintained for more than 15 days, without any changes.

Other infectious syndromes were present in 29 patients $(72.5 \%)$, being the urinary tract the most commonly affected body system (51.7\%), followed by burned area skin infections $(27.6 \%)$ and pneumonia $(20.7 \%)$. To treat and prevent all these infections, antibiotics were given to 38 patients (95\%), with $57.9 \%$ of them used for therapeutic purposes.

Gram-negative bacilli were isolated in the majority $(77.3 \%)$ of all catheter-related infections and more than half of them were caused by Acinetobacter sp. species. Pseudomonas sp. and members of the Enterobacteriacae family were found in $23.5 \%$ and $14.7 \%$, respectively, while Burckolderia cepacea and Alcalygenes sp. accounted for the other species. Gram-positive bacteria was recovered from 10 catheter infections, with Staphylococcus aureus being isolated in $50 \%$ of this episodes, followed by negativecoagulase staphylococcus in $40 \%$. Enterococcus faecalis was detected in one patient $(10 \%)$.
Catheter-related infections treatment was based solely on catheter withdraw for half of the patients and catheter withdraw plus antibiotic therapy were used for all the others patients, with one exception (exclusive antibiotic treatment). Mortality rate of $12.5 \%$ was found regardless of treatment used.

\section{DISCUSSION}

Few recent studies worldwide have evaluated infections other than scar wounds in burned patients. ${ }^{11-13}$ Among those, four non-Brazilian population-based study publications were found considering catheter-related infection in these particular patients. ${ }^{3,5-7}$ Our prevalence of $4.51 \%$ catheter infections in burned patients is two-fold higher when compared with general intensive care units, as published in CDC guidelines. ${ }^{8}$

Concerning social-epidemiological aspects, it is worth noting that home burns by flame were the commonest accidents, rather than energy contact explosions-related injuries in labor environments, since PAHBCU is geographically located in a region surrounded by sugar-cane industries. Diabetes mellitus was the leading co-morbidity as expected, due to its higher prevalence in most of our patients. Signs of infection at the insertion site and sepsis represent the least critical condition diagnosed in burned patients with catheter-related infections, explaining the relatively low mortality rate found in this study $(12.5 \%)$, compared to other critically ill settings.

Almost all catheters used were single-lumen types, which led to a large variety of fluids (including parenteral nutrition) administered and over handling in the same line, increasing colonization and catheter infection, against CDC recommendations, suggesting the need for an exclusive line for parenteral nutrition. Although subclavian vein is the safest access to prevent infection, many catheters had to be placed in burned areas, usually associated with high bacterial counts, a well-known risk factor for such infections in these patients. ${ }^{6}$ Moreover, the overwhelming majority of catheters in the present study were placed longer than 10 days, contributing to extensive handling and thus colonization. To overcome this problem, King and collaborators ${ }^{7}$ proposed a three-day programmed catheter changes in burned patients. However, its applicability as a definitive measure for catheter related infection is yet to be proved.

Surprisingly, Gram-negative bacilli were the most common group isolated. Acinetobacter sp. has been associated with colonization of deeply immunosuppressed patients, especially those with open wounds or submitted to invasive devices, and it was the most common pathogen isolated in PAHBCU. Indeed, there are recent studies showing an important role played by this agent in burned patients. ${ }^{15,16} \mathrm{De}-$ spite the well recognized role of Acinetobacter as a colonizer of respiratory and urinary tracts, rather than acting as an 
invasive microbe,${ }^{17}$ our study suggest that this agent can be very efficient in gaining blood stream from central-venous catheters in large burned patients. This result contradicts the microbial etiology described in the only two specific papers on the same subject in which Staphylococcus sp. was the main agent recovered in two different burn units., ${ }^{3,14}$

This finding points to the possibility that Acinetobacter sp. constitute an emerging concern in burn units, especially in catheter related infections, maybe comparable to Staphylococcus aureus and other gram-positive agents. If this proves to be important, a probable high rate of blood stream Acinetobacter sp. invasion should be expected, leading to a proper systemic antimicrobial therapeutic choice. ${ }^{18}$

The low mortality rate here described is consistent with literature reports for most of the non-severe catheter infections, and the main treatment strategy used in the studied patients was simple catheter withdraw, which seemed to be effective in infection controlling.

Although this is a retrospective and descriptive study, with a relatively low number of cases, limitations that we acknowledge, these data can open doors for future investigation in a large number of patients, in different treatment centers, in order to incriminate Acinetobacter sp. as one of the major pathogens causing catheter-related infections in burned patients.

\section{REFERENCES}

1. Santucci SG, Gobara S, Santos CR, Fontana C, Levin AS. Infections in a burn intensive care unit: experience of seven years. J Hosp Infect 2003; 53(1):6-13.

2. Bang RL, Gang RK, Sanyal SC, Mokaddas E, Ebrahim MK. Burn septicemia: an analysis of 79 patients. Burns 1998; 24:354-61.

3. Tymonová J, Adámková M, Torsová V, Kadlcík M, Kackanin J, Crkvenjas Z. Catheter Related Infections at The Burn Centre of the University Hospital in Ostrava. Acta Cirurgiae Plasticae 2008; 50:23-6.

4. Gang RK, Sanyal SC, Bang RL, Mokaddas E, Lari AR. Staphylococcal septicemia in burns. Burns 2000; 26:359-366.
5. Lesseva M. Central venous catheter-related bacteremia in burn patients. Scandinavian Journal of Infectious Disease 1998; 30(6):585-9.

6. Ramos GE, Bolgiani AN, Patino O, Prezzavento GE, Guastavino P, Durlach R, Fernandez C, Liliana B, Benaim F. Catheter Infection Risk Related to the Distance Between Insertion Site and Burned Area. Journal of Burn Care \& Rehabilitation 2002; 23(4):226-71.

7. King B, Schulman CI, Pepe A, Pappas P, Varas R, Namias N Timing of Central Venous Catheter Exchange and Frequency of Bacteremia in Burn Patients. Journal of Burn Care \& Research 2007; 28(6):859-60.

8. MMWR. Guidelines of the Prevention of Intravascular Catheter-Related Infections. Centers for Disease Control 2002;51(RR100);1-26.

9. Maki DG, Weise CE, Safarin HW. A semiquantitative culture method for identifying intravenous-catheter-related infection. N Engl J Med 1977; 296:1305-9.

10. www.survivingsepsiscampgain.org. Acesso 25/03/2009.

11. Askarian M, Reza S, Hosseini R, Kheirandish P, Ziad A Memish. Incidence of urinary tract and bloodstream infections in Ghotbeddin Burn Center, Shiraz 2000-2001. Burns 2003; 29(5):455-9.

12. Edelman DE, Khan N, Kempf K, White MM. Pneumonia after inhalation injury. J Burn Care Res 2007; 28(2):241-6.

13. Eckert MJ, Wade TD, Davis KA et al. Ventilator-associated pneumonia after combined burn and trauma is caused by associated injuries and not the burn wound. J Burn Care Res 2006; 27(4):457-62.

14. Still JM, Law E, Thyruvaiyaru D, Belcher K, Donker K. CentralLine Related Sepsis in Acute Burn Patients. Am Surg 1998; 64:165-70.

15. Albrecht MC, Griffith ME, Murray CK et al. Impact of Acinetobacter infection on the mortality of burn patients. J Am Coll Surg 2006; 203(4):546-50.

16. Babík J, Bodnárová L, Sopko K. Acinetobacter - A serious danger for burn patients. Acta Cirurgiae Plasticae 2008; 50:27-33.

17. Bayat A, Shaaban H, Dodgson A, Dunn KW. Implications for Burns Unit design following outbreak of multi-resistant Acinetobacter infection in ICU and Burns Unit. Burns 2003; 29(4):303-6.

18. Trottitier V, Gonzales SP, Namias N, King D, Pizano S, Shulman C. Outcomes of Acinetobacter baumannii infection in critically ill burned patients. Journal of Burn Care \& Research 2007; 28(2):248-54. 